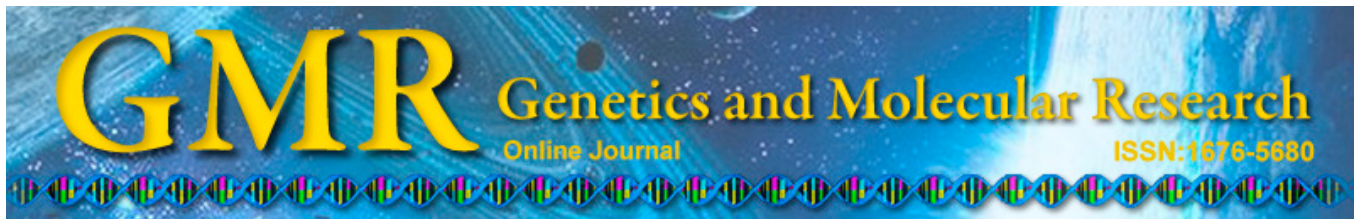

\title{
Impact of early postoperative enteral nutrition on clinical outcomes in patients with gastric cancer
}

\author{
B. Li, H.Y. Liu, S.H. Guo, P. Sun, F.M. Gong and B.Q. Jia \\ Department of Surgical Oncology, \\ General Hospital of the People's Liberation Army, Beijing, China \\ Corresponding author: B.Q. Jia \\ E-mail: jiabaoqing1971@126.com \\ Genet. Mol. Res. 14 (2): 7136-7141 (2015) \\ Received July 7, 2014 \\ Accepted November 18, 2014 \\ Published June 29, 2015 \\ DOI http://dx.doi.org/10.4238/2015.June.29.7
}

\begin{abstract}
The impact of early enteral nutrition (EEN) on clinical outcomes of gastric cancer patients was investigated. Three hundred patients undergoing gastric cancer surgery from July 2010 to May 2014 were randomly divided into experimental and control groups $(n=150$ / group). Experimental group patients received enteral nutrition in water during the early postoperative period. Control group patients received conventional perioperative treatment. Patients' clinical outcomes, postoperative immune function, and nutritional statuses were compared, which revealed that the postoperative fever duration $(80.2 \pm 6.0 \mathrm{vs} 88.1$ $\pm 8.1 \mathrm{~h}, \mathrm{P}<0.05)$, anal exhaust time $(78.8 \pm 9.3$ vs $85.3 \pm 8.4 \mathrm{~h}, \mathrm{P}<$ $0.05)$, and length of hospitalization $(7.73 \pm 2.13$ vs $9.77 \pm 1.76$ days, $\mathrm{P}<0.01)$ differed significantly. Treatment costs in thousands of dollars were $31.24 \pm 3.21$ for the experimental group and $35.61 \pm 2.32$ for the control group; this difference was statistically significant $(\mathrm{P}<0.01)$. The incidence of postoperative complications did not significantly differ between the experimental and control groups [14.0\% (21/150) vs $17.3 \%$ (26/150), $\mathrm{P}>0.05]$. At postoperative days 3 and 7 , the $\mathrm{CD}^{+}, \mathrm{CD}^{+}$, natural killer cell, albumin, and prealbumin levels and $\mathrm{CD}^{+} / \mathrm{CD}^{+}$ra-
\end{abstract}


tio were significantly higher in the experimental group than the control group (all $\mathrm{P}<0.05)$. $\mathrm{CD} 8^{+}$cell counts were significantly lower in the experimental group than the control group $(\mathrm{P}<0.05)$. Postsurgical oral EEN can improve nutritional status and immune function and promote early recovery of intestinal function in patients with gastric cancer.

Key words: Gastric cancer; Enteral nutrition; Intestinal function; Immune function; Nutritional status

\section{INTRODUCTION}

Patients with gastric cancer often experience postsurgical eating difficulties because of increased catabolism, weakened anabolism, and decreased immune function. These effects can lead to (or aggravate) malnutrition and increase the incidence of postoperative complications and mortality (Li et al., 2014). Proper nutritional support can significantly improve patients' postsurgical quality of life. A previous study reported that early oral intake is safe and effective for patients after gastric cancer surgery (Hur et al., 2009). This study investigated the impact of early oral enteral nutrition intake on the clinical outcomes of patients after gastric cancer surgery.

\section{MATERIAL AND METHODS}

\section{Study participants}

The patient inclusion criteria included pathologically confirmed gastric cancer and acceptance of semi-elective surgery. The exclusion criteria included distant tumor metastasis, the presence of additional major diseases of the liver, kidney, heart, lung, brain, and other organs, severe obesity [body mass index (BMI) $>30 \mathrm{~kg} / \mathrm{m}^{2}$ ], severe malnutrition (BMI $<15 \mathrm{~kg} /$ $\mathrm{m}^{2}$ ), the presence of endocrine and metabolic diseases or disorders such as hyperthyroidism and hypothyroidism, and contraindications of enteral nutrition such as intestinal obstruction, intestinal perforation, and intestinal necrosis.

According to the aforementioned criteria, 300 patients with gastric cancer admitted to the General Hospital of the People's Liberation Army from July 2010 to May 2014 were included in this study. The patients were randomly divided into experimental and control groups using a random number table method that allotted 150 cases to each group. Patients in both groups were healthy before surgery with no history of preoperative radiotherapy, chemotherapy, or other special treatments such as traditional Chinese medicine. General information about the patients in the 2 groups is shown in Table 1 . The procedure of this study was approved by the Ethics Committee of the General Hospital of the People's Liberation Army, and all patients enrolled provided signed informed consent.

All patients underwent open radical gastrectomy performed by the same group of physicians. Patients were excluded from the study after surgery if advanced stage tumors were detected, the radical surgery could not be completed, the pancreas and spleen were injured, or a perforation with abdominal infection occurred because of the tumor. The same preoperative preparation was performed for the 2 groups of patients. At 30 minutes prior to surgery and within $48 \mathrm{~h}$ after surgery, second-generation cephalosporin was used to prevent infection. At postoperative day 3 , an analgesia pump was provided for self-controlled analgesia. 


\begin{tabular}{|c|c|c|c|c|c|c|c|c|}
\hline \multirow[t]{2}{*}{ Group } & \multirow[t]{2}{*}{$\mathrm{N}$} & \multirow{2}{*}{$\begin{array}{c}\text { Age (year) } \\
\text { Means } \pm \text { SD }\end{array}$} & \multicolumn{2}{|c|}{ Gender $(\mathrm{N})$} & \multirow{2}{*}{$\begin{array}{l}\text { BMI }\left(\mathrm{kg} / \mathrm{m}^{2}\right) \\
\text { Means } \pm \mathrm{SD}\end{array}$} & \multicolumn{3}{|c|}{ Surgical procedure $(\mathrm{N})$} \\
\hline & & & Male & Female & & $\begin{array}{l}\text { Distal subtotal } \\
\text { gastrectomy }\end{array}$ & $\begin{array}{l}\text { Proximal subtotal } \\
\text { gastrectomy }\end{array}$ & $\begin{array}{c}\text { Total } \\
\text { gastrectomy }\end{array}$ \\
\hline Experimental group & 150 & $59.2 \pm 9.7$ & 76 & 74 & $22.3 \pm 2.2$ & 68 & 51 & 31 \\
\hline Control group & 150 & $60.4 \pm 9.2$ & 78 & 72 & $22.4 \pm 2.0$ & 80 & 45 & 25 \\
\hline$P$ value & & 0.553 & 0.995 & & 0.965 & 0.206 & & \\
\hline
\end{tabular}

$\mathrm{BMI}=$ body mass index; $\mathrm{SD}=$ standard deviation.

\section{Treatment methods}

A postoperative nasoenteral feeding tube was not provided to patients in the experimental group. Instead, a small amount of drinking water was provided beginning on the first day after surgery. If there was no reported discomfort, $500 \mathrm{~mL}$ of fractionated oral enteral nutrition [Jevity, Abbott B.V., Hoofddorp, Netherlands; product contained 2196.6 kJ (525 kcal), $20 \mathrm{~g}$ protein, $17 \mathrm{~g}$ fat, $70 \mathrm{~g}$ carbohydrates, and $5.3 \mathrm{~g}$ total dietary fiber in $500 \mathrm{~mL}$ ] and water were given on postoperative day 2. On postoperative day 3,1000 $\mathrm{mL}$ of oral Jevity was given multiple times in addition to a small amount of liquid diet. Subsequently, $1000 \mathrm{~mL}$ of oral Jevity was given daily, and the amount of liquid or semi-liquid diet was increased modestly. The Jevity solutions were maintained at $35-41^{\circ} \mathrm{C}$ to avoid any discomfort due to cold stimulation that might affect the experimental results. The amount of intravenous fluid was gradually decreased as the enteral nutrition volume increased.

The control group received traditional perioperative treatment consisting of a nasoenteral feeding tube and postoperative intravenous infusion. After anal exhaust, the nasoenteral feeding tube was removed and the patient began to drink water orally. If there was no discomfort, the intake of water and liquid and semi-liquid diets were gradually increased. After patients from both groups achieved the same discharge criteria (i.e., full recovery of liquid or semi-liquid diet without intravenous fluids, no drainage tube and vacuum catheter, no complications, and capable of free movement), subjects were allowed to continue rehabilitation at home.

\section{Outcome measures}

The postoperative fever duration, anal exhaust time, length of postoperative hospital stay, and hospitalization cost were recorded. Blood samples from patients were collected before surgery and at postoperative days 1,3 , and 7 after fasting. The levels of $\mathrm{CD} 3^{+}, \mathrm{CD} 4^{+}, \mathrm{CD} 8^{+}$, and natural killer (NK) cells as well as the $\mathrm{CD}^{+} / \mathrm{CD}^{+}$ratio were detected using flow cytometry to compare the patients' postoperative immune function. The albumin and prealbumin levels before surgery and at postoperative days 1,3, and 7 were determined to compare the patients' postoperative nutritional statuses. Postoperative complications, including gastrointestinal symptoms (nausea, vomiting, bloating, and diarrhea), pulmonary infection, abdominal infection, wound infection, urinary tract infection, and anastomotic fistula, were documented.

\section{Statistical methods}

All data were analyzed using the SPSS 17.0 statistical software package (SPSS, Inc., Chicago, IL, USA). Normal measurement data are reported as means \pm standard deviations. 
Comparisons between groups were conducted using an independent sample Student $t$-test. Counting data between groups were compared using the $\chi^{2}$ test.

\section{RESULTS}

\section{General information}

No patients were excluded during surgery, and there were no cases of perioperative death or postoperative anastomotic fistula. The incidence of complications in the experimental group was $14.0 \%(21 / 150)$, including 1 patient with wound infection that was resutured and monitored for 15 days before discharge, 1 patient with urinary tract infection who exhibited improved symptoms after oral levofloxacin treatment, and 2 patients with bloating, nausea, and vomiting who exhibited improved symptoms after nasogastric tube indwelling. The incidence of complications in the control group was $17.3 \%(26 / 150)$, including 1 patient with wound infection that was monitored for 10 days before discharge, 1 patient with urinary tract infection, 1 patient with pulmonary infection that required conservative treatment before discharge, and 2 patients with diarrhea that gradually improved after modulating the intestinal flora. Patients in the experimental group had a significantly shortened postoperative fever duration, anal exhaust time, and length of postoperative hospital stay with significantly reduced hospital costs when compared with the control group. The results are shown in Table 2.

\begin{tabular}{lcccccc}
\multicolumn{2}{l}{ Table 2. General postoperative information of patients in the 2 groups. } \\
\hline Group & $\mathrm{N}$ & $\begin{array}{c}\text { Postoperative } \\
\text { fever duration }\end{array}$ & $\begin{array}{c}\text { Anal exhaust } \\
\text { time }\end{array}$ & $\begin{array}{c}\text { Length of postoperative } \\
\text { hospital stay }\end{array}$ & $\begin{array}{c}\text { Incidence of } \\
\text { complications }\end{array}$ & Hospital costs \\
\cline { 3 - 7 } & & (Means $\pm \mathrm{SD}, \mathrm{h})$ & $($ Means $\pm \mathrm{SD}, \mathrm{h})$ & $($ Means $\pm \mathrm{SD}$, days $)$ & {$[\mathrm{N}(\%)]$} & (Means $\pm \mathrm{SD}$, thousands of dollars) \\
\hline $\begin{array}{l}\text { Experimental } \\
\text { group }\end{array}$ & 150 & $80.2 \pm 6.0$ & $78.8 \pm 9.3$ & $7.73 \pm 2.13$ & $21(14.0)$ & $4.8 \pm 0.84$ \\
$\begin{array}{l}\text { Control group } \\
\text { P value }\end{array}$ & 150 & $88.1 \pm 8.1$ & $85.3 \pm 8.4$ & $9.77 \pm 1.76$ & $26(17.3)$ & $5.5 \pm 0.75$ \\
\hline
\end{tabular}

$\mathrm{SD}=$ standard deviation.

\section{Immune function and nutritional status}

Immune indicators (levels of $\mathrm{CD}^{+}, \mathrm{CD}^{+}, \mathrm{CD}^{+}$, and $\mathrm{NK}$ cells as well as the $\mathrm{CD}^{+} /$ $\mathrm{CD}^{+}$ratio) and nutritional indicators (albumin and prealbumin) did not significantly differ between the 2 groups preoperatively or at postoperative day 1 . However, the levels of $\mathrm{CD}^{+}$, $\mathrm{CD}^{+}$, and NK cells as well as the $\mathrm{CD}^{+} / \mathrm{CD}^{+}$ratio were significantly higher in the experimental group when compared with the control group at postoperative days 3 and 7 . The CD ${ }^{+}$ cell count was significantly decreased and the levels of albumin and prealbumin were significantly increased in the experimental group when compared with the control group at postoperative days 3 and 7 . The results are shown in Table 3. 
Table 3. Immunological and nutritional indicators of the 2 groups.

\begin{tabular}{llccccc}
\hline Indicator & Groups & $\mathrm{N}$ & Preoperative & Postoperative day 1 & Postoperative day 3 & Postoperative day 7 \\
\hline $\mathrm{CD}^{+}(\%)$ & Experimental group & 150 & $36.0 \pm 4.5$ & $22.7 \pm 1.1$ & $34.1 \pm 4.3^{*}$ & $35.8 \pm 4.7^{*}$ \\
& Control group & 150 & $35.9 \pm 5.1$ & $22.8 \pm 2.0$ & $28.1 \pm 3.6$ & $30.6 \pm 4.1$ \\
$\mathrm{CD} 4^{+}(\%)$ & Experimental group & 150 & $42.5 \pm 3.2$ & $36.1 \pm 3.0$ & $38.6 \pm 3.1^{*}$ & $40.4 \pm 3.8^{*}$ \\
& Control group & 150 & $42.9 \pm 3.3$ & $35.9 \pm 2.7$ & $31.9 \pm 2.6$ & $35.8 \pm 3.4$ \\
$\mathrm{CD} 8^{+}(\%)$ & Experimental group & 150 & $24.1 \pm 2.8$ & $25.6 \pm 2.9$ & $19.8 \pm 2.3^{*}$ & $17.0 \pm 3.1^{*}$ \\
& Control group & 150 & $24.5 \pm 2.1$ & $20.2 \pm 3.4$ & $24.5 \pm 2.5$ & $22.2 \pm 2.6$ \\
$\mathrm{CD} 4 / \mathrm{CD} 8$ & Experimental group & 150 & $1.78 \pm 0.20$ & $1.45 \pm 0.33$ & $1.66 \pm 0.17^{*}$ & $1.78 \pm 0.21^{*}$ \\
& Control group & 150 & $1.75 \pm 0.22$ & $1.62 \pm 0.45$ & $1.44 \pm 0.18$ & $1.46 \pm 0.23$ \\
$\mathrm{NK}(\%)$ & Experimental group & 150 & $21.6 \pm 3.6$ & $19.8 \pm 3.4$ & $25.1 \pm 4.9^{*}$ & $26.6 \pm 5.7^{*}$ \\
& Control group & 150 & $22.5 \pm 4.7$ & $21.6 \pm 5.4$ & $20.1 \pm 5.7$ & $22.5 \pm 5.3$ \\
Prealbumin (g/L) & Experimental group & 150 & $171.1 \pm 23.7$ & $141.5 \pm 17.7$ & $157.3 \pm 17.4^{*}$ & $163.6 \pm 14.6^{*}$ \\
& Control group & 150 & $167.4 \pm 21.0$ & $140.5 \pm 21.2$ & $145.8 \pm 17.9$ & $146.7 \pm 16.5$ \\
Albumin $(\mathrm{g} / \mathrm{L})$ & Experimental group & 150 & $30.5 \pm 7.0$ & $28.4 \pm 6.9$ & $33.1 \pm 5.0^{*}$ & $35.1 \pm 6.9^{*}$ \\
& Control group & 150 & $31.3 \pm 6.7$ & $29.4 \pm 4.3$ & $29.3 \pm 4.4$ & $30.7 \pm 7.2$ \\
\hline
\end{tabular}

$* \mathrm{P}<0.05$ compared to control group. $\mathrm{NK}$, natural killer cell.

\section{DISCUSSION}

Since the concept of nutritional support was originally proposed, strategies have undergone continuous changes. Currently, researchers largely agree that "enteral nutrition support is preferred as long as the gastrointestinal tract is functioning" (Heidegger et al., 2008). A study by Gabor et al. (2005) demonstrated that it is safe to begin enteral nutrition at $6 \mathrm{~h}$ postoperatively. Other studies have reported that gastric cancer patients who received early oral postoperative intake instead of through an indwelling nasogastric tube did not show an increased incidence of postoperative complications (Chen et al., 2014). In the present study, the incidence of postoperative complications for patients in the experimental group (without a nasoenteral feeding tube, receiving EEN) did not significantly differ from that of the control group $(\mathrm{P}>0.05)$. This finding supports the use of postoperative EEN. Some scholars believe that enteral nutrition with dietary fiber can be used as the preferred form of enteral nutrition without an increase in the incidence of gastrointestinal complications in patients with wellfunctioning gastrointestinal tracts (Yang et al., 2012; Yu et al., 2014). In the present study, the Jevity enteral nutrition formulation was used. This formulation contains essential nutrients, including dietary fiber, casein, minerals, and vitamins as well as a high number of calories; in addition, the supplement is easily digested and absorbed with a smaller amount of residue.

Serum albumin and prealbumin levels were used as indicators of the patients' nutritional statuses. In this study, the albumin and prealbumin levels of patients in the experimental group were significantly higher than those of patients in the control group at postoperative days 3 and $7(\mathrm{P}<0.05)$. These data indicate that postoperative EEN improves the nutritional statuses of patients with gastric cancer; this might have been due to the high-caloric supplement, which was quickly absorbed by the intestine to promote rapid protein synthesis. Studies have reported that enteral nutrition can improve the protein kinetics and immune function of patients after major abdominal surgery (Elliott et al., 2013; Feng et al., 2013). In general immunology, $\mathrm{CD} 8^{+} \mathrm{T}$ cells are strong effector $\mathrm{T}$ cells (also known as cytotoxic $\mathrm{T}$ cells). Classical regulatory or suppressor $\mathrm{T}$ cells are of the $\mathrm{CD} 4^{+}$lineage (although $\mathrm{CD} 4^{+} \mathrm{T}$ cells can also be effector cells). All mature $\mathrm{T}$ cells express $\mathrm{CD}^{+} ; \mathrm{CD}^{+}$and $\mathrm{CD} 4^{+} \mathrm{T}$ cells are helper $\mathrm{T}$ lymphocytes that promote anti-tumor immunity. $\mathrm{CD} 8^{+}$cells are suppressor $\mathrm{T}$ lymphocytes. In this study, the levels of $\mathrm{CD}^{+}$and $\mathrm{CD} 4^{+}$cells as well as the $\mathrm{CD} 4^{+} / \mathrm{CD} 8^{+}$ratios were significantly 
increased and the level of $\mathrm{CD} 8^{+}$cells was significantly decreased in the experimental group when compared with the control group at postoperative days 3 and 7 . These data indicate that postoperative EEN improves postoperative immune function in patients with gastric cancer.

The results of this study also showed that postoperative EEN reduces the postoperative fever duration, anal exhaust time, and length of postoperative hospital stay in patients with gastric cancer. We believe that enteral nutrition directly provides nutrients to the intestinal mucosa, ensures an energy supply for the gut-associated lymphoid tissue and immune cells such as lymphocytes and macrophages, and maintains the stability of immune cell structures and functions; therefore, EEN promotes the postoperative recovery of immune functioning, effectively inhibits the inflammatory response, and shortens postoperative fever time. In addition, the enteral nutrition formulation contains dietary fiber, which absorbs intestinal water and promotes intestinal peristalsis, thereby facilitating the postoperative recovery of intestinal function.

A previous study found that accelerated postoperative rehabilitation reduced health care costs for patients with gastric cancer ( $\mathrm{Li}$ et al. 2014). In the present study, the total hospital costs for gastric cancer patients in the experimental group were significantly lower than those for patients in the control group. This lower cost is related to the rapid recovery of gastrointestinal function after surgery, shorter hospital stay, and reduced parenteral nutrition. EEN significantly benefits patients with gastric cancer by accelerating rehabilitation after surgery.

\section{REFERENCES}

Chen ZX, Liu AH and Cen Y (2014). Fast-track program vs traditional care in surgery for gastric cancer. World $J$. Gastroenterol. 20: 578-583.

Elliott JA, Patel VM, Kirresh A, Ashrafian H, et al. (2013). Fast-track laparoscopic bariatric surgery: a systematic review. Updates Surg. 65: 85-94.

Feng F, Ji G, Li JP, Li XH, et al. (2013). Fast-track surgery could improve postoperative recovery in radical total gastrectomy patients. World J. Gastroenterol. 19: 3642-3648.

Gabor S, Renner H, Matzi V, Ratzenhofer B, et al. (2005). Early enteral feeding compared with parenteral nutrition after oesophageal or oesophagogastric resection and reconstruction. Br. J. Nutr. 93: 509-513.

Heidegger CP, Darmon P and Pichard C (2008). Enteral vs parenteral nutrition for the critically ill patient: a combined support should be preferred. Curr. Opin. Crit. Care. 14: 408-414.

Hur H, Si Y, Kang WK, Kim W, et al. (2009). Effects of early oral feeding on surgical outcomes and recovery after curative surgery for gastric cancer: pilot study results. World J. Surg. 33: 1454-1458.

Li H, Han X, Su L, Zhu W, et al. (2014). Laparoscopic radical gastrectomy versus traditional open surgery in elderly patients with gastric cancer: Benefits and complications. Mol. Clin. Oncol. 2: 530-534.

Yang DJ, He WL, Zhang S, Chen HY, et al. (2012). Fast track surgery accelerates the postoperative rehabilitation and recovery of insulin sensitivity in elective operation for colorectal carcinoma: a randomized controlled clinical trial. Zhonghua Wai Ke Za Zhi. 50: 870-874.

Yu Z, Zhuang CL, Ye XZ, Zhang CJ, et al. (2014). Fast-track surgery in gastrectomy for gastric cancer: a systematic review and meta-analysis. Langenbecks Arch. Surg. 399: 85-92. 